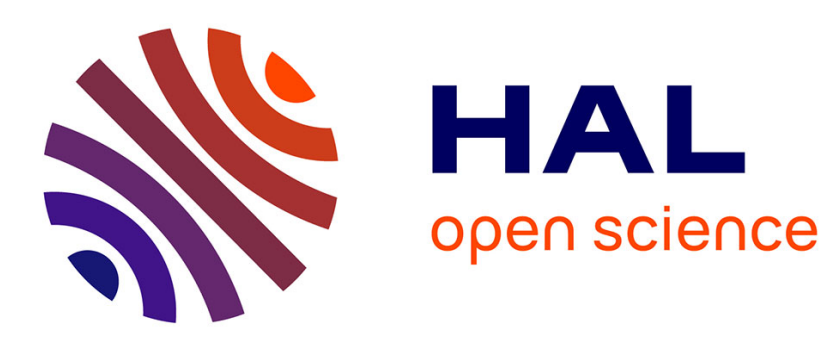

\title{
Phenomenological model of soot production inside a non-buoyant laminar diffusion flame
}

\author{
Guillaume Legros, Jose L Torero
}

\section{To cite this version:}

Guillaume Legros, Jose L Torero. Phenomenological model of soot production inside a non-buoyant laminar diffusion flame. Proceedings of the Combustion Institute, 2015, 35 (3), pp.2545-2553. 10.1016/j.proci.2014.05.038 . hal-01524579

\section{HAL Id: hal-01524579 \\ https://hal.sorbonne-universite.fr/hal-01524579}

Submitted on 18 May 2017

HAL is a multi-disciplinary open access archive for the deposit and dissemination of scientific research documents, whether they are published or not. The documents may come from teaching and research institutions in France or abroad, or from public or private research centers.
L'archive ouverte pluridisciplinaire HAL, est destinée au dépôt et à la diffusion de documents scientifiques de niveau recherche, publiés ou non, émanant des établissements d'enseignement et de recherche français ou étrangers, des laboratoires publics ou privés. 


\title{
Phenomenological model of soot production inside a non-buoyant laminar diffusion flame
}

\author{
G. Legros ${ }^{*, a}$, J.L. Torero ${ }^{b}$
}

a Sorbonne Universités, UPMC Univ Paris 06, CNRS, UMR 7190 Institut

Jean le Rond d'Alembert, F-75005 Paris, France

b School of Civil Engineering, The University of Queensland, QLD 4072,

Australia

${ }^{*}$ Corresponding author:

Guillaume Legros, Sorbonne Universités, UPMC Univ Paris 06, CNRS, UMR 7190 Institut Jean le Rond d'Alembert, F-75005 Paris, France, Fax: +33130 8548 99, Email: guillaume.legros@upmc.fr

Name of Colloquium : $\quad$ Fire Research

Alternative Colloquium : Laminar Flames

Estimate of total length $=5851$

Method of determination : Method 2, LaTeX users, complete two-column formatted version

Main text $\quad=4381$

References $\quad=418$

Tab. $1=59$

Tab. $2 \quad=167$

Fig. $1=123$

Fig. $2 \quad=303$

Fig. $3=195$

Fig. $4=205$ 


\title{
Phenomenological model of soot production inside a non-buoyant laminar diffusion flame
}

\author{
G. Legros ${ }^{*, a}$, J.L. Torero ${ }^{b}$ \\ ${ }^{a}$ Sorbonne Universités, UPMC Univ Paris 06, CNRS, UMR 7190 Institut Jean le Rond \\ d'Alembert, F-75005 Paris, France \\ ${ }^{b}$ School of Civil Engineering, The University of Queensland, QLD 4072, Australia
}

\begin{abstract}
An original phenomenological model for soot production inside a laminar, flat plate boundary layer diffusion flame is presented. The model is compared with experimental measurements conducted in microgravity. For the experiments, the fuel, ethylene, is injected through a flat porous burner into an oxidizer stream flowing parallel to the burner surface. The oxidizer is a mixture of $35 \%$ oxygen and $65 \%$ nitrogen. The fuel and oxidizer velocities are systematically varied. The analysis of the data shows that the streamwise location of the maximum flame height can be considered an unambiguous characteristic length of the flame as opposed to the maximum visible flame length. Analysis of the streamwise location of the maximum flame height enables to establish the transition between "open-tip" and "closed-tip" behavior as well as scaling laws for the soot volume fraction. A scaled soot volume fraction is found to follow a linear relationship with the streamwise coordinate normalized by the burner length. This correlation appears to be valid for the whole range of conditions investigated, knowing that this range does not cover the blow-off regime.
\end{abstract}

Keywords: Soot, diffusion flame, microgravity 


\section{Introduction}

Soot production is one of the most complex phenomena driving fire spread since it stands at the heart of coupling between chemistry, heat generation and heat transfer [1]. Under microgravity and low characteristic forced velocities conditions, the absence of natural convection allows to dramatically expand the time scales associated with transport and combustion processes, increasing both soot concentration [2] and radiative emissions, especially from the soot continuum [3]. Radiation from soot can then be the predominant mode of heat transfer involved in non-buoyant flame spread, even for small diffusion flames [4]. Therefore, predicting soot production is crucial within the context of spacecraft fire safety.

Soot production is the result of two competitive processes, formation and oxidation. Models of both processes have been extensively developed for the last two decades and their numerical resolution has been shown to adequately predict local soot concentrations [5-9]. Because of the extensive computations involved by numerous elementary reactions and species, detailed soot models [5] have not been yet fully incorporated into CFD codes. Integrations of lighter semi-empirical soot production models [6-8] exhibited some fair results but their accuracy seems to be strongly flame configuration dependent. While a more comprehensive numerical approach by Blanquart and Pitsch [9] has been validated over a relatively wide range of academic configurations, the methodology followed requires a large database from every configuration studied. Therefore, a phenomenological model of soot production can consolidate the database associated with a specific configuration, sustaining the 
aforementioned methodology.

Several studies provided significant insights into the phenomenological prediction of fuels' sooting propensity in laminar axisymmetric jet diffusion flames at both normal gravity [10-12] and microgravity $[2,13,14]$. Originally proposed by Markstein and De Ris [10], the smoke point concept underlies these studies which infer soot production along the flame axis only from the flame characteristics at the fuel smoke point. This concept also suggests that the flame quenches due to radiative heat losses at a fixed soot concentration. Flames can be "closed-tip" (below the smoke point), if fuel is consumed before this critical concentration is attained, or "open-tip" (beyond the smoke point) if quenching occurs before the fuel is fully consumed, soot particles being released through the open flame tip. Flame length, and consequently other processes influenced by the flame length, such as co-current flame spread over a solid plate [15], could then be linked to the critical soot concentration.

All these studies supported the notion of the practical importance of the smoke point approach but conceded large discrepancies originating as early as the fuel entry nozzle, i.e. at the location of the first soot inception $[11,12,14]$. The origin of the error was attributed to coarse approximations in the chemistry of soot formation. The disagreement becomes even more significant in the quenching region of "open-tip" flames, which possibly results from the lack of an adequate radiative heat transfer model. Thus, analytical models are still incapable of predicting the geometry, therefore the structure of "open-tip" flames [13].

Consequently, several questions remain. First, the mechanisms by which a critical soot concentration for flame quenching is attained have not been 
comprehensively described. Furthermore, it still remains unclear where the combustion reaction ceases as opposed to soot oxidation. For "open-tip" flames, the visible flame length does not necessarily match the reactive zone because, due to the high temperatures, soot may continue to oxidize beyond the end of the visible reaction [13]. These issues can only be addressed if the soot concentration evolution can be tracked along the reactive zone. This leads to the need to define the soot history, as local soot concentration will strongly depend on the history that precedes the arrival of soot to a specific location [16]. Of critical importance is the effect of oxygen concentration on the formation and oxidation, which connects soot history and local soot concentrations to the structure of the flow field in the vicinity of the flame. The global residence time, defined as the ratio of the characteristic flame length to the governing mass transport velocity, seems to be a key parameter controlling soot concentrations $[2,14]$. Konsur et al. [14] determined experimentally that the peak soot volume fraction decreased when the characteristic global residence time was reduced and Mortazavi et al. [17] extended similar observations to a wider range of conditions.

A flat plate burner configuration allows the influence of the flow conditions on the soot production to be assessed. With this configuration, Legros et al. $[18,19]$ extended the above studies to quantify the influence of the oxidizer velocity on soot concentrations showing that increasing the oxidizer velocity $\mathrm{V}_{\text {Ox }}$ while maintaining the fuel supply rate enhances both soot oxidation and soot formation, with the latter dominating in the fuel injection region and the former near the flame trailing edge. In these experiments it was found that an increase in the global residence time leads to a decrease in 
the peak soot volume fraction, in contrast with the observations of Konsur et al. [14]. A subsequent numerical study proved that the orientation of the flow streamlines was intrinsically related to the observed changes in soot volume fraction fields [20]. Fuentes et al. [21] argued that acceleration of the oxidizer flow external to the flame resulted in reduced soot oxidation, therefore increased soot volume fraction leading to longer flames. In these "open-tip" flames, the trailing edge is indeed at the quenching limit. Torero et al. [15] explored this limit determining that the reason for the elongation is an increase in the Damköhler number at the trailing edge as $V_{O X}$ increases. Finally, Legros et al. [22] used scaling analysis arguments that qualitatively assessed the influence of the fuel and oxidizer velocities on the ratio of the soot formation characteristic time to the soot oxidation characteristic time, therefore on the resulting local soot concentrations.

The present study extends the work of Legros et al. [22] by formulating an original phenomenological model for net soot production that is then contrasted with the experimental results previously reported by Legros et al. $[18,22]$. To this end, new processings of both the visible flame imaging and the soot volume fraction field are performed.

\section{Investigated configuration}

\subsection{Experimental setup}

The diffusion flame is established inside an oxidizing boundary layer over a flat plate burner. A schematic of the experimental configuration, together with details on the experimental configuration can be found in Ref.18. In the following, the streamwise and the transverse coordinates are $x$ and $y$, 
respectively. $z$ is the height above the flat plate.

Ethylene is selected as fuel due to its well characterized sooting behavior. It is injected via a mass flow controller through a porous square plate, which has a $50 \mathrm{~mm} \times 50 \mathrm{~mm}$ effective section of injection. In the following, the characteristic length of injection is referred as $L_{p}=50 \mathrm{~mm}$.

The oxidizer flow is introduced into the combustion chamber via mass flow controllers through a settling chamber and honeycomb plates. The oxidizer creates a boundary layer flow parallel to the burner surface where the diffusion flame is established. The oxidizer consists of a mixture of $35 \% \mathrm{O}_{2}$ and $65 \% \mathrm{~N}_{2}$. This mixture was chosen since an increased $\mathrm{O}_{2}$ partial pressure emphasizes $\mathrm{CH}^{*}$ radicals spontaneous emission. $\mathrm{CH}^{*}$ emission measurements enable the correction for three-dimensional effects affecting the line-of-sight measurements of light attenuation [18]. In the following, $\mathrm{V}_{\mathrm{F}}$ and $\mathrm{V}_{\mathrm{OX}}$ are the fuel mean velocity and the oxidizer mean velocity, respectively, as inferred from the measured mass flow rates.

Microgravity conditions are attained by means of parabolic flights. Every parabola provides $22 \mathrm{~s}$ of microgravity. The limitations imposed by low quality microgravity and g-jitter have been analyzed in detail by Rouvreau et al. [25].

\subsection{Diagnostics}

The geometry of the visible flame is provided by a Sony $720 \times 480$ pixel triCCD camera that captures 30 side views of the flame per second. This camera was focused on the symmetry plane $(\mathrm{y}=0)$ using a Nikor $60-\mathrm{mm} \mathrm{f} / 2.8$ lens. With this optical arrangement, each pixel in the CCD array focused light from 
a volume corresponding to $0.3 \mathrm{~mm}$ in height (z-direction), $0.3 \mathrm{~mm}$ in width (x-direction) and $10 \mathrm{~mm}$ in depth (y-direction). The width of the burner allows assuming that the flame is two-dimensional within this depth although three-dimensional effects are present but have been well characterized $[18$, 23]. The tri-CCD technology enables the discrimination among the green, blue, and red spectra emitted by the flames. The information on flame shape extracted from these frames will allow here the evaluation and the comparison of flame characteristics lengths, given that the exposure time was kept constant (30 ms).

To obtain a quantitative characterization of soot concentration, a line-ofsight light attenuation technique was shown to provide both high sensitivity and fine spatial resolution [18]. To this end, a $100 \mathrm{~mW}$ laser diode emitting at $\lambda=532 \mathrm{~nm}$ was used as a backlighting source. Light attenuation through the flame is attributed to soot particles at this wavelength. The light attenuation was measured with an 8-bit monochromatic and progressive 720x480 pixel CCD camera. Using the Mie's theory in the Rayleigh's limit, the soot volume fraction $\mathrm{f}_{\text {soot }}(\mathrm{x}, \mathrm{z})$ was inferred from the attenuation measurements. More details on the technique and the correction applied for the slight threedimensional effects, i.e. the weak dependency of the absorption field on the transverse coordinate, are given in Ref. 18. The technque was shown to produce valid soot volume fraction fields for $0.4 \leq x / L_{P} \leq 1.1$ at a rate of $30 \mathrm{~Hz}$.

With these rates, every parabola provided 450 visible side views and 450 soot volume fraction fields after the flame reached its steady state. 


\section{Scaling soot production}

The scale analysis derived by Legros et al. [22] is here briefly summarized. In addition, "closed-tip" and "open-tip" flames are treated separately to allow for a meaningful extension of the analysis.

\subsection{Generic scale analysis}

Earlier Direct Numerical Simulations showed that the soot oxidation characteristic time $\tau_{\text {ox }}$ is governed by the oxidizer velocity $\mathrm{V}_{\mathrm{Ox}}$ while the soot formation characteristic time $\tau_{f}$ is driven by the fuel diffusion velocity $V_{d}$ into the boundary layer [22]. The ratio $\tau_{f} / \tau_{o x}$ then depends on the velocities ratio $\mathrm{V}_{\mathrm{OX}} / \mathrm{V}_{\mathrm{d}}$ as follows:

$$
\frac{\tau_{f}}{\tau_{\mathrm{ox}}} \sim \frac{\mathrm{V}_{\mathrm{OX}}}{\mathrm{V}_{\mathrm{d}}}
$$

Defining $V_{d}$ then scaling it leads to the following relationship:

$$
\mathrm{V}_{\mathrm{d}} \approx \mathrm{D}_{\mathrm{F}} \frac{\mathrm{Y}_{\mathrm{F}, 0}}{\mathrm{~h}_{f l}}
$$

where $\mathrm{D}_{\mathrm{F}}$ is the fuel mass diffusivity, $\mathrm{h}_{f l}$ the flame characteristic height in the $z$-direction (normal to the flat plate), and $Y_{F, 0}$ the fuel mass fraction at the injection location $(z=0)$. Here, $\mathrm{Y}_{\mathrm{F}, 0}=1$ and $\mathrm{h}_{f l}$ is the maximum flame height.

Scaling the conservation of momentum in the streamwise direction for this boundary layer problem enables the introduction of the aerodynamic characteristic height $\mathrm{h}_{\mathrm{CL}}$ and the flame length $\mathrm{l}_{f l}$ in the streamwise direction:

$$
\mathrm{h}_{\mathrm{CL}} \approx\left(\mathrm{D}_{\mathrm{F}} \frac{\mathrm{l}_{f l}}{\mathrm{~V}_{\mathrm{OX}}}\right)^{1 / 2}
$$


where the Schmidt number has been assumed to be unity, i.e. $D_{F}$ is equal to the kinematic viscosity.

Scaling the equation of mass conservation links $\mathrm{h}_{f l}$ to $\mathrm{h}_{\mathrm{CL}}$ through the constant $s[26]$ :

$$
\mathrm{h}_{f l} \approx s \mathrm{~h}_{\mathrm{CL}}
$$

with

$$
s=\frac{\mathrm{Y}_{\mathrm{F}, 0}}{\mathrm{Y}_{\mathrm{OX}, \infty}} \frac{\nu_{\mathrm{OX}} w_{\mathrm{OX}}}{\nu_{\mathrm{F}} w_{\mathrm{F}}}
$$

$\mathrm{Y}_{\mathrm{OX}, \infty}$ being the oxygen mass fraction in the surrounding, $\nu_{\mathrm{OX}}$ the oxygen stoichiometric coefficient, $\nu_{\mathrm{F}}$ the fuel stoichiometric coefficient, $w_{\mathrm{OX}}$ the oxygen molar mass, and $w_{\mathrm{F}}$ the fuel molar mass.

Eqs. (2-4) are combined to express $\mathrm{V}_{\mathrm{d}}$ as a function of $\mathrm{V}_{\mathrm{OX}}$ and $\mathrm{l}_{f l}$ :

$$
\mathrm{V}_{\mathrm{d}} \approx \frac{1}{s}\left(\mathrm{D}_{\mathrm{F}} \frac{\mathrm{V}_{\mathrm{OX}}}{\mathrm{l}_{f l}}\right)^{1 / 2}
$$

Finally, the ratio of the characteristic times depends on $\mathrm{V}_{\mathrm{OX}}$ and $\mathrm{l}_{f l}$ as follows:

$$
\frac{\tau_{f}}{\tau_{o x}} \sim \mathrm{V}_{\mathrm{OX}}{ }^{1 / 2} \mathrm{l}_{f l}^{1 / 2}
$$

A further assumption is then required to express this ratio as a function of the problem parameters $\mathrm{V}_{\mathrm{OX}}$ and $\mathrm{V}_{\mathrm{F}}$.

\subsection{Full fuel consumption}

For "closed-tip" flames, the fuel mass flow rate injected can be considered fully consumed at the flame, leading to the following relationship:

$$
\rho_{F} \mathrm{~V}_{\mathrm{F}} \mathrm{L}_{\mathrm{p}}^{2} \approx \rho_{f l} \mathrm{~V}_{\mathrm{d}} \mathrm{l}_{f l} \mathrm{~L}_{\mathrm{p}}
$$


where $\rho_{F}$ and $\rho_{f l}$ are the specific densities at the conditions of the fuel injection and the flame, respectively. In the above equation, $\rho_{f l} \mathrm{~V}_{\mathrm{d}}$ represents the fuel mass flow rate per unit area to the flame, whose characteristic length in the transverse direction has been shown to be $\mathrm{L}_{\mathrm{p}}$ [23].

The flame length can then be inferred using Eq.(6):

$$
l_{f l}=\frac{1}{\mathrm{D}_{\mathrm{F}}}\left(s \mathrm{~L}_{\mathrm{p}} \frac{\rho_{F}}{\rho_{f l}} \mathrm{~V}_{\mathrm{F}}\right)^{2} \frac{1}{\mathrm{~V}_{\mathrm{OX}}}
$$

that when introduced in Eq.(7) results in:

$$
\frac{\tau_{f}}{\tau_{o x}} \sim \mathrm{V}_{\mathrm{F}}
$$

Eq.(10) shows that soot production inside a "closed- tip" flame is independent of $\mathrm{V}_{\mathrm{OX}}$ while its length will decrease with an oxidizer velocity increase according to Eq.(9). "Closed-tip" non-buoyant axisymmetric diffusion flames indeed exhibit these trends $[13,14]$.

\subsection{Partial fuel consumption}

For "open-tip" flames, the fuel mass flow rate injected cannot be considered fully consumed at the flame. Within the range of experimental conditions investigated, the non-buoyant ethylene diffusion flames established over the flat plate were shown to be of "open-tip" kind $[19,24]$. In the vicinity of the trailing edge of such flames, the flame visible emissions then follow smooth decaying functions. Therefore, the exact location of the final quenching of the flame and its relationship to visible emissions are difficult to define and always requires the definition of an arbitrary threshold.

Still, the streamwise location of the maximum flame height, called $x_{\max }$ hereafter, can also be considered a characteristic length of the flame. Earlier 
studies $[19,24]$ especially showed that the visible flame enveloppe remains above the soot layer for $x \leq x_{\max }$ then moves toward this layer with $x$. The soot volume fraction fields mapped all along the flame by Laser Induced Incandescence [24] allow to identify $x_{\max }$ as the streamwise location of the maximum soot volume fraction. Downstream $x_{\max }$, soot oxidation starts dominating soot formation.

\section{Phenomenological model of soot production}

New processings of both the visible flame imaging and the soot volume fraction field sustain here for the first time an original definition of the flame characteristic length, leading to a proper phenomenological model of net soot production above the fuel injection area.

\subsection{Characteristic length scale}

Figure 1 exhibits the enveloppes of the visible flame for a fuel velocity

of $6.4 \mathrm{~mm} . \mathrm{s}^{-1}$ and an oxidizer velocity of $150 \mathrm{~mm} . \mathrm{s}^{-1}$. These enveloppes have been detected on a single image provided by the tri-CCD camera that captures side view of the flame. This image was selected among the 450 images recorded at these flow conditions because it captured a visible flame whose $x_{\max }$ is very close from the mean $x_{\max }$ inferred from this set of images.

For every of the red, green, and blue frames constituting an image, a grey scale threshold value between the oxidizer and the fuel sides was determined from the histogram of grey scale values. The flame sheet corresponding to this threshold was extracted by an edge detection algorithm. The edge shapes were then found to be fairly insensitive to the selected threshold values for 
$x \leq x_{\max }$ but quite sensitive for $x \geq x_{\max }$.

At the flame's leading edge, the blue contribution to the flame's visible emissions is especially attributed to the chemiluminescence emitted by $\mathrm{CH}^{*}$ radicals. These radicals are shown to be central to many hydrocarbon combustion chemical pathways as they originate from the early reaction between $\mathrm{O}_{2}$ and $\mathrm{C}_{2} \mathrm{H}$. Thus, the leading edge of the blue contour in Fig.1 appears slightly shitfed upstream the other two.

As an illustration of the smooth decaying functions followed by the visible emissions at the flame's trailing edge, the flame length that can be inferred from Fig. 1 is very sensitive to the selected contour due to the discrepancy among the trailing edges. In this sooty flame, the visible emissions at the trailing edge are dominated by soot radiation, whose peak belongs to the infra-red part of the spectrum. Therefore, the detected location of the flame's trailing edge is a smooth decreasing function of the wavelength in the visible part of the spectrum.

Interestingly, from the flame's leading edge to the location of its maximum height $x_{\max }$, the flame shape is less sensitive to the selected contour, therefore, the determination of $x_{\max }$ is also quite unambiguous. Indeed, along this region, the ethylene primary reaction zone still defines the flame's enveloppe. Thus, in the vertical direction, the overlap between the temperature and the soot volume fraction profiles is quite thin (see the narrow peaks of green emission in Fig.2(a) in Ref.22). This results in very close peaks of the visible emissions.

From the three contours shown in Fig.1, a mean $x_{\max }$ can be inferred, together with an error bar whose lower and upper bounds are given by the blue 
and the red arrows, respectively. Over the range of experimental conditions investigated, the width of the error bar never exceeded $5 \%$ of $x_{\max }$. For this reason, $x_{\max }$ is from now considered as the characteristic length scale $\mathrm{l}_{f l}$ of the investigated flame.

Figure 2 exhibits images provided by the tri-CCD camera for different oxidizer and fuel velocities. For a matter of legibility, the color images have been here converted into grayscale frames. The arrows indicate the streamwise locations of the mean $x_{\max }$ extracted as mentioned above. For a given set of conditions, the image shown was selected among the 450 images recorded along the microgravity period because it captured a visible flame exhibiting an $x_{\max }$ very close from the $x_{\max }$ averaged over the 450 frames.

At any oxidizer velocity, $x_{\max }$ globally increases with the fuel velocity. When the fuel velocity, therefore the fuel volume flow rate, is increased, the flame shape spreads over in the streamwise direction. Indeed, at a constant oxygen flow rate to the flame, the supplemental fuel meets the fresh oxidizer further downstream, potentially enabling its oxidation. Furthermore, increasing the fuel velocity thickens the flame as the fuel's advection to the flame is enhanced. The flame then represents a stronger obstacle to the oxidizer flow, which results in a higher flame. This trend has been numerically investigated in details in Ref. 20 on this configuration. Non-buoyant axisymmetric jet diffusion flames exhibit a similar trend [13].

At the highest fuel velocity shown in Fig. 2, both the visible flame length and the characteristic flame length $x_{\max }$ increase with the oxidizer velocity. This is unconsistent with Eq.(9), therefore is a further evidence that the flames studied here cannot be of "closed- tip" kind. Thus, extinction occurs 
before the full fuel load consumption. For these specific conditions, according to Eq.(7), $\tau_{f} / \tau_{o x}$ will increase with $\mathrm{V}_{\mathrm{OX}}$ as the observed flame length does. In contradiction with a classical residence time consideration, enhancing oxidizing convection leads here to a local increase in soot production (see the evolution with $\mathrm{V}_{\mathrm{OX}}$ of the soot volume fraction in Fig.2(c) in Ref.22). This non-intuitive result needs to be complemented as, when $\mathrm{V}_{\mathrm{OX}}$ is increased, the soot load will also partially burn downstream, which makes the visible flame longer.

At the intermediate fuel velocity shown in Fig. 2, the evolution of $x_{\max }$ with $\mathrm{V}_{\mathrm{OX}}$ follows a similar trend but the increase looks reduced.

At the lowest fuel velocity shown in Fig. 2, a reverse trend reveals. From $\mathrm{V}_{\mathrm{OX}}=100 \mathrm{~mm} \cdot \mathrm{s}^{-1}$ to $150 \mathrm{~mm} . \mathrm{s}^{-1}$, both the visible flame length and the characteristic flame length $x_{\max }$ still increase with the oxidizer velocity. Conversely, both lengths decrease from $\mathrm{V}_{\mathrm{OX}}=150 \mathrm{~mm} \cdot \mathrm{s}^{-1}$ to $200 \mathrm{~mm} \cdot \mathrm{s}^{-1}$. This latter trend is in a qualitative agreement with Eq.(9). This means that the flame approaches the conditions that would enable the full soot oxidation, therefore would make the flame of "closed-tip" kind. Soot production has been lowered, which in turn weakens the radiative quenching of the flame at its trailing edge.

Figure 3 exhibits the evolutions of $x_{\max }$ with $\mathrm{V}_{\mathrm{OX}}$ (lower x-axis) for $\mathrm{V}_{\mathrm{F}}=6.4 \mathrm{~mm} \cdot \mathrm{s}^{-1}$, and with $\mathrm{V}_{\mathrm{F}}$ (upper $\mathrm{x}$-axis) for $\mathrm{V}_{\mathrm{OX}}=200 \mathrm{~mm} \cdot \mathrm{s}^{-1}$. The symbols correspond to the experimental data. The variations of $x_{\max }$ due to the selection of the contour were found to be negligible as compared to the fluctuations with time induced by g-jitters. Therefore, the error bars shown in Fig. 3 are inferred from the standard deviation of $x_{\max }$ among the 450 
images recorded along the microgravity period.

The evolution of $x_{\max }$ with $\mathrm{V}_{\mathrm{OX}}$ confirms the observations of Fig.2. The value of $x_{\text {max }}$ increases first with the flow velocity, reaches a maximum, and then starts to decrease. As explained before, for airflows larger than those of the maximum, the behavior is that of a "closed-tip" flame, thus follows Eq.(9). The hyperbola expected in such a configuration is represented by the dashed line in Fig.3. This curve was calibrated with the experimental point at the highest $\mathrm{V}_{\mathrm{Ox}}$ investigated. Within the range of investigated conditions, the flame length moves away from this tendency as the oxidizer velocity is decreased and radiative quenching approaches $x_{\max }$. Nonetheless, as shown by the green curve in Fig.3, the evolution of $x_{\max }$ with $\mathrm{V}_{\mathrm{F}}$ appears to follow a fairly quadratic trend, which here remains in agreement with Eq.(9). Thus, the transition between "open-tip" and "closed-tip" behaviors is clearly a strong function of both fuel and oxidizer velocities.

Finally, the level of oxidizer flow rate requested to mitigate the limiting phenomenon that radiative quenching is increases with the fuel velocity, therefore the soot production. Interestingly, when radiative quenching moves away from $x_{\max }$, i.e. $\mathrm{V}_{\text {Ox }}$ increases, the fluctuations of $x_{\max }$ weaken, leaving the region around $x_{\max }$ more stable.

\subsection{Predictive model}

For $100 \mathrm{~mm} \cdot \mathrm{s}^{-1} \leq \mathrm{V}_{\mathrm{OX}} \leq 300 \mathrm{~mm} \cdot \mathrm{s}^{-1}$ and at a given $\mathrm{V}_{\mathrm{F}}, x_{\max }$ may be considered constant with an associated error that does not exceed $\pm 7 \%$. If this phenomenological trend now leads to assess that $x_{\max } \sim o\left(\mathrm{~V}_{\mathrm{OX}}\right)$ while $x_{\max } \sim O\left(\mathrm{~V}_{\mathrm{F}}^{2}\right)$, then the ratio $\tau_{f} / \tau_{o x}$ may be inferred from Eq.(7) as a 
function of the problem parameters $\mathrm{V}_{\mathrm{OX}}$ and $\mathrm{V}_{\mathrm{F}}$ :

$$
\frac{\tau_{f}}{\tau_{o x}} \sim \mathrm{V}_{\mathrm{F}} \mathrm{V}_{\mathrm{OX}}^{1 / 2}
$$

This tendency should especially scale the evolution of the integrated soot volume fraction $\mathrm{F}_{\text {soot }}(x)$ (see Fig. 2(c) in Ref. 22) along the flame:

$$
\mathrm{F}_{\text {soot }}(\mathrm{x})=\int_{\mathrm{z}=0}^{\mathrm{z}_{\max }(\mathrm{x})} \mathrm{f}_{\text {soot }}(\mathrm{x}, \mathrm{z}) \mathrm{dz}
$$

Figure 4 indeed supports the relevance of the phenomenological model revealed by Eq.(11). Processing the raw soot volume fraction (see the upper graph in Fig.4) as prescribed in Eq.(12), the lower graph exhibits the unified evolution of the scaled integrated soot volume fraction $\mathrm{F}_{\text {soot }}^{*}=\mathrm{F}_{\text {soot }} /\left(\mathrm{V}_{\mathrm{F}} \mathrm{V}_{\mathrm{OX}}{ }^{1 / 2}\right)$ with the normalized streamwise coordinate $x / L_{p}$. For a matter of legibility, a restricted set of conditions are shown here. Over the ranges of oxidizer and fuel velocities investigated, all evolutions of the scaled integrated soot volume fraction actually followed this unique trend.

Any curve plotted in the lower graph in Fig. 4 represents the mean evolution of the scaled integrated soot volume fraction that was computed from the 450 soot volume fraction fields measured within one parabola. As shown by the thick solid line in Fig. 4, the following linear regression is expected to decently model the phenomenological model:

$$
\frac{\mathrm{F}_{\text {soot }}}{\mathrm{V}_{\mathrm{F}} \mathrm{V}_{\mathrm{OX}}{ }^{1 / 2}}=a \frac{x}{L_{p}}+b
$$

The coefficients $a$ and $b$ were determined using a trust-region-reflective algorithm [27] that minimizes the least-squares between the results of Eq.(13) and the set of experimental scaled integrated soot volume fractions. The coefficients are reported in Tab.1. 
To provide with an uncertainty assessment of this linear model, a confidence interval was inferred from all the soot volume fraction fields measured. The lower and upper bounds $C I$ of the confidence interval were evaluated using Eq. (14):

$$
C I\left(\frac{x}{L_{p}}\right)=\overline{\mathrm{F}_{\text {soot }}^{*}}\left(\frac{x}{L_{p}}\right) \pm 1.96 \sigma_{\max }\left(\frac{x}{L_{p}}\right)
$$

where $\overline{\mathrm{F}_{\text {soot }}^{*}}$ is the average value of the scaled integrated soot volume fractions measured at the streamwise location $x / L_{p}$ and $\sigma_{\max }$ is the maximum value among the standard deviations exhibited by every set of conditions $\left(\mathrm{V}_{\mathrm{F}}, \mathrm{V}_{\mathrm{OX}}\right)$ at the specific $x / L_{p}$. The interval $\pm 1.96 \sigma_{\max }$ represents $95 \%$ of the area under the standard distribution curve [28]. For both the lower and the upper bounds of the confidence interval, the linear regressions were also inferred as prescribed above. Table 1 also provides with the values of the coefficients a and $b$ defining the lower and upper linear bounds shown in Fig. 4(bottom). The relevance of the linear model expressed by Eq.(13) is fairly assessed as all the measured scaled integrated soot volume fractions fall inside the shaded zone encompassed between the upper and lower bounds of the confidence interval.

It must be reminded here that this model was established for some restricted conditions. These are specified in Tab.2, together with the associated uncertainties.

\section{Conclusion}

Steady ethylene diffusion flames were established over a flat plate inside an oxidizing boundary layer in microgravity. Over the ranges of fuel and 
oxidizer velocities investigated, these "open-tip" flames experience radiative quenching, which makes the flame trailing edge, therefore the flame length, difficult to track. Nonetheless, side view of the visible flame allowed the extraction of the flame shape. The streamwise location of the maximum flame height detected along this shape was shown to be a relevant and unambiguous characteristic flame length substituting the intuitive definition. A maximum of this characteristic flame length was observed to occur at velocities below those typical of natural convection. Beyond this maximum the flame exhibits "closed-tip" behavior and shrinks with the oxidizer velocity.

Complementing a former scale analysis, the aforementioned experimental trends of the characteristic flame length sustained the relevance of the dependency of the ratio of the soot formation characteristic time to the soot oxidation characteristic time on the characteristic flow velocities. This dependency was shown to scale the net soot production measured over the fuel injection area. The phenomenological model supports an explanation of the experimental observations: the soot production locally increases over the fuel injection area with the oxidizer flow velocity, leading to longer flame length, what no numerical study incorporating soot model exhibited up to now. However, this scaling could not be extended to the range of conditions leading to blow-off which was not investigated here.

Consequently, such a phenomenological model of soot production is especially expected to deliver an original and meaningful contribution to the validation of numerical tools currently developed to predict fire spread into spacecraft. Moreover, the present scale analysis could help identify similar models that govern soot production into devices that reduce buoyancy, such 
as pipe or channel.

\section{Acknowledgments}

This work was funded by CNES and ESA. Parabolic flights campaigns took place on board the Novespace A300-ZeroG. Insights offered by Dr A. Fuentes and Dr P. Joulain are most appreciated. 


\section{References}

[1] P. Chatterjee, J.L. de Ris, Y. Wang, S.B. Dorofeev, Proc. Combust. Inst. 33 (2011) $2665-2671$.

[2] C.M. Megaridis, B. Konsur, D.W. Griffin, Proc. Combust. Inst. 26 (1996) 1291-1299.

[3] W. Kong, F. Liu, Combust. Theory Modelling 13 (2009) 993-1023.

[4] S.L. Olson, J.S. T'ien, Combust. Flame 121 (2000) 439-452.

[5] M. Frenklach, H. Wang, Proc. Combust. Inst. 23 (1991) 1559-1566.

[6] I.M. Kennedy, C. Yam, D.C. Rapp, R.J. Santoro, Combust. Flame 107 (1996) 368-382.

[7] M.D. Smooke, C.S. McEnally, L.D. Pfefferle, R.J. Hall., M.B. Colket, Combust. Flame 117 (1999) 117-139.

[8] S.J. Brookes, J.B. Moss, Combust. Flame 116 (1999) 486-503.

[9] G. Blanquart, H. Pitsch, Combust. Flame 156 (2009) 1614-1626.

[10] G.H. Markstein, J. De Ris, Proc. Combust. Inst. 20 (1985) 1637-1646.

[11] C.W. Lautenberger, J.L. de Ris, N.A. Dembsey, J.R. Barnett, H.R. Baum, Fire Safety J. 40 (2005) 141-176.

[12] T. Beji, J.P. Zhang, W. Yao, M. Delichatsios, Combust. Flame 158 (2011) 281-290.

[13] K.C. Lin, G.M. Faeth, P.B. Sunderland, D.L. Urban, Z.G. Yuan, Combust. Flame 116 (1999) 415-431.

[14] B. Konsur, C.M. Megaridis, D.W. Griffin, Combust. Flame 118 (1999) 509-520.

[15] J.L. Torero, T. Vietoris, G. Legros, P. Joulain, Combust. Sci. Technol. 174 (2002) $187-203$.

[16] I.M. Kennedy, Prog. Energy Combust. Sci. 23 (1997) 95-132.

[17] S. Mortazavi, P.B. Sunderland, J. Jurng, Ü.Ö. Köylü, G.M. Faeth, AIAA paper (1993) 93-708.

[18] G. Legros, P. Joulain, J.P. Vantelon, D. Bertheau, A. Fuentes, J.L. Torero, Combust. Sci. Technol. 178 (2006) 813-835.

[19] G. Legros, A. Fuentes, P. Ben-Abdallah, J. Baillargeat, P. Joulain, J.P. Vantelon, J.L. Torero, Opt. Lett. 30 (2005) 3311-3313.

[20] S. Rouvreau, P. Joulain, H.Y. Wang, P. Cordeiro, J.L. Torero, Proc. Combust. Inst. 29 (2002) 2527-2534.

[21] A. Fuentes, G. Legros, S. Rouvreau, P. Joulain, J.P. Vantelon, J.L. Torero, Combust. Sci. Technol. 179 (2007) 3-19. 
[22] G. Legros, A. Fuentes, S. Rouvreau, P. Joulain, B. Porterie, J.L. Torero, Proc. Combust. Inst. 32 (2009) 2461-2470.

[23] L. Brahmi, T. Vietoris, S. Rouvreau, P. Joulain, L. David, J.L. Torero, AIAA Journal 43 (2005) 1725-1733.

[24] A. Fuentes, G. Legros, A. Claverie, P. Joulain, J.P. Vantelon, J.L. Torero, Proc. Combust. Inst. 31 (2007) 2685-2692.

[25] S. Rouvreau, P. Cordeiro, J.L. Torero, P. Joulain, Proc. Combust. Inst. 30 (2005) $519-526$.

[26] I. Glassman, Combustion, Academic Press, UK, 1977, p. 398.

[27] T.F. Coleman and Y.Y. Li, SIAM J. Optimiz. 6 (1996) 418-445.

[28] J.F. Kenney and E.S. Keeping, Confidence limits for the binomial parameter, Van Nostrand, Princeton, NJ, USA, 1962. 
Table 1: Values of the coefficients $a$ and $b$ in Eq.(13) for the evaluation of the scaled integrated soot volume fraction.

\begin{tabular}{lll}
\hline $\mathrm{F}_{\text {soot }} /\left(\mathrm{V}_{\mathrm{F}} \mathrm{V}_{\mathrm{OX}}{ }^{1 / 2}\right)$ & $\mathrm{a}$ & $\mathrm{b}$ \\
$10^{6} \mathrm{~mm} \cdot \mathrm{s}^{3 / 2} \cdot \mathrm{mm}^{-3 / 2}$ & & \\
\hline mean & 0.260 & 0.116 \\
lower bound & 0.283 & 0.082 \\
upper bound & 0.242 & 0.149
\end{tabular}


Table 2: Conditions investigated to assess the phenomenological model.

\begin{tabular}{lll}
\hline quantity & value & uncertainty \\
\hline ambient pressure & 1 atm & \pm 0.01 atm \\
ambient temperature & $298 \mathrm{~K}$ & $\pm 2 \mathrm{~K}$ \\
fuel & $\mathrm{C}_{2} \mathrm{H}_{4}$ & $99.9 \%$ purity \\
$\mathrm{O}_{2}$ content of the oxidizer & $35 \%$ & $\pm 1 \%$ \\
balance gas & $\mathrm{N}_{2}$ & $99.9 \%$ purity \\
oxidizer velocity & $100 \mathrm{~mm} \cdot \mathrm{s}^{-1} \leq \mathrm{V}_{\mathrm{Ox}} \leq 300 \mathrm{~mm} \cdot \mathrm{s}^{-1} \pm 3 \%$ \\
fuel velocity & $3.3 \mathrm{~mm} \cdot \mathrm{s}^{-1} \leq \mathrm{V}_{\mathrm{F}} \leq 10 \mathrm{~mm} \cdot \mathrm{s}^{-1}$ & $\pm 3 \%$ \\
region investigated & $0.4 \leq x / \mathrm{L}_{p} \leq 1.1$ & -
\end{tabular}




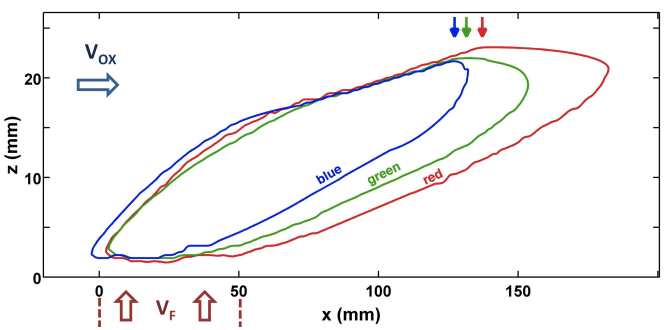

Figure 1: Contours extracted from a single side view image of the visible flame. This image is composed of the three frames provided by the three CCDs (blue, green, red) of the camera that capture the blue, green, and red parts of the flame's visible emissions. The flame was established for $\mathrm{V}_{\mathrm{OX}}=150 \mathrm{~mm} \cdot \mathrm{s}^{-1}$ and $V_{F}=6.4 \mathrm{~mm} \cdot \mathrm{s}^{-1}$. The arrows at the top of the contours indicate the streamwise locations $x_{\max }$ of the flame maximum height detected along the blue, green, and red contours (from the left to the right). 


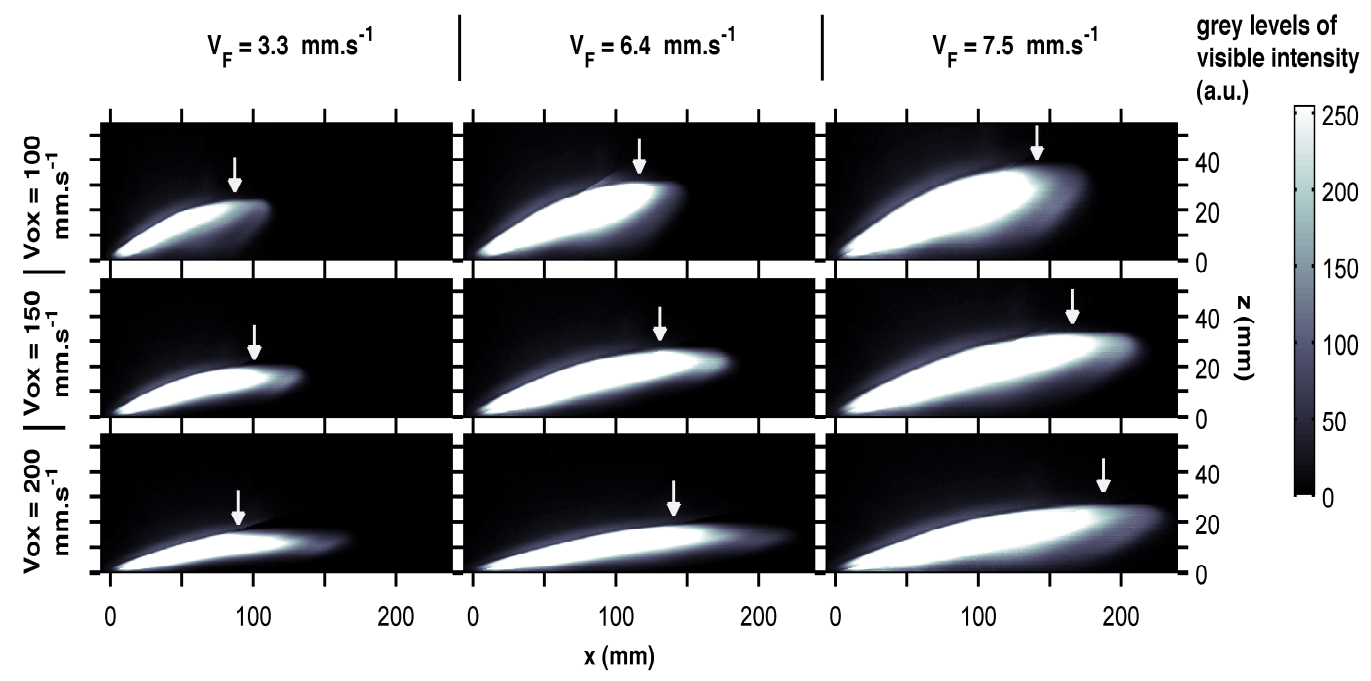

Figure 2: Side views imaging the visible ethylene flames for different oxidizer and fuel velocities. The arrows indicate the streamwise locations $x_{\max }$ of the maximum flame height. 


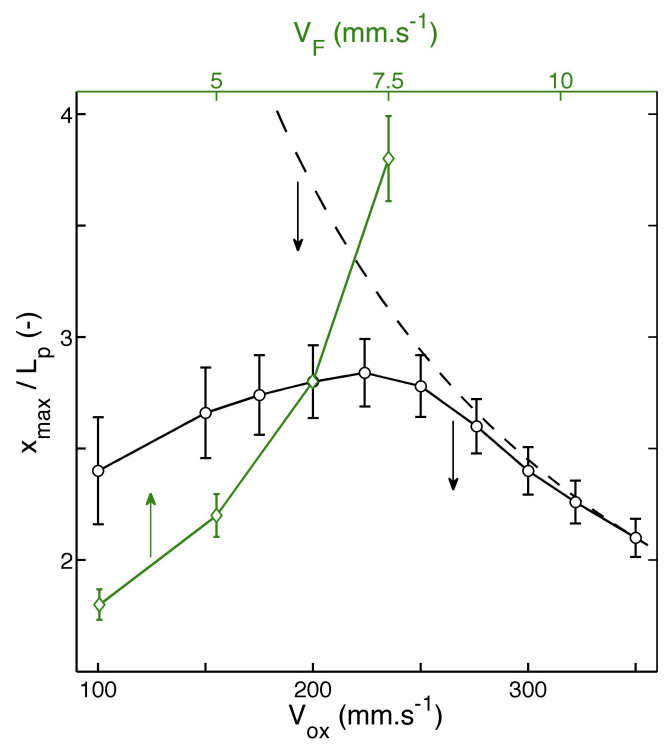

Figure 3: Normalized streamwise location $x_{\max }$ of the maximum flame height as a function of $\mathrm{V}_{\mathrm{OX}}$ for $V_{F}=6.4 \mathrm{~mm} \cdot \mathrm{s}^{-1}$ (black lower x-axis), and as a function of $\mathrm{V}_{\mathrm{F}}$ for $V_{O X}=200$ $\mathrm{mm} . \mathrm{s}^{-1}$ (green upper $\mathrm{x}$-axis). The black circles and the green diamonds represent the experimental points. The dashed line is the hyperbola given by Eq.(9) and calibrated with the experimental point at $\mathrm{V}_{\mathrm{OX}}=350 \mathrm{~mm} \cdot \mathrm{s}^{-1}$. 


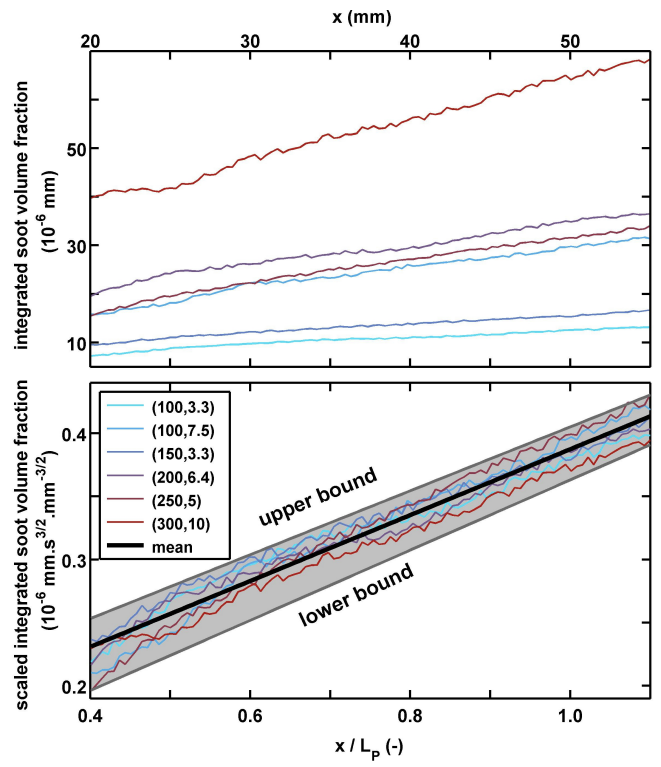

Figure 4: Evolutions of: (top) the integrated soot volume fraction $\mathrm{F}_{\text {soot }}$ with the streamwise coordinate $x$; (bottom) the scaled integrated soot volume fraction $\mathrm{F}_{\text {soot }} /\left(\mathrm{V}_{\mathrm{F}} \mathrm{V}_{\mathrm{OX}}{ }^{1 / 2}\right)$ with the normalized streamwise coordinate $x / L_{p}$. The couples of values in the legend specify the oxidizer and the fuel velocities $\left(\mathrm{mm} \cdot \mathrm{s}^{-1}\right)$, respectively. 


\section{List of Figures}

1 Contours extracted from a single side view image of the visible flame. This image is composed of the three frames provided by the three CCDs (blue, green, red) of the camera that capture the blue, green, and red parts of the flame's visible emissions. The flame was established for $\mathrm{V}_{\mathrm{OX}}=150 \mathrm{~mm} \cdot \mathrm{s}^{-1}$ and $V_{F}=6.4 \mathrm{~mm} \cdot \mathrm{s}^{-1}$. The arrows at the top of the contours indicate the streamwise locations $x_{\max }$ of the flame maximum height detected along the blue, green, and red contours (from the left to the right). . . . . . . . . . . .

2 Side views imaging the visible ethylene flames for different oxidizer and fuel velocities. The arrows indicate the streamwise locations $x_{\max }$ of the maximum flame height. . . . . . . . . . Normalized streamwise location $x_{\max }$ of the maximum flame height as a function of $\mathrm{V}_{\mathrm{OX}}$ for $V_{F}=6.4 \mathrm{~mm} \cdot \mathrm{s}^{-1}$ (black lower x-axis), and as a function of $\mathrm{V}_{\mathrm{F}}$ for $V_{O X}=200 \mathrm{~mm} \cdot \mathrm{s}^{-1}$ (green upper x-axis). The black circles and the green diamonds represent the experimental points. The dashed line is the hyperbola given by Eq.(9) and calibrated with the experimental point at $\mathrm{V}_{\mathrm{OX}}=350 \mathrm{~mm} \cdot \mathrm{s}^{-1}$. . .

4 Evolutions of: (top) the integrated soot volume fraction $\mathrm{F}_{\text {soot }}$ with the streamwise coordinate $x$; (bottom) the scaled integrated soot volume fraction $\mathrm{F}_{\text {soot }} /\left(\mathrm{V}_{\mathrm{F}} \mathrm{V}_{\mathrm{OX}}{ }^{1 / 2}\right)$ with the normalized streamwise coordinate $x / L_{p}$. The couples of values in the legend specify the oxidizer and the fuel velocities $\left(\mathrm{mm} . \mathrm{s}^{-1}\right)$, respectively. . . . . . . 